\title{
Factors Associated with Mental Depression among Men Who Have Sex with Men in Southern India
}

\author{
Sangram Kishor Patel ${ }^{1}$, Parimi Prabhakar², Niranjan Saggurti1 \\ ${ }^{1}$ HIV and AIDS Program, Population Council, New Delhi, India \\ ${ }^{2}$ Regional Office, India HIV/AIDS Alliance, Hyderabad, India \\ Email: sangramkishor@gmail.com, skpatel@popcouncil.org
}

Received 17 August 2015; accepted 19 September 2015; published 22 September 2015

Copyright (C) 2015 by authors and Scientific Research Publishing Inc.

This work is licensed under the Creative Commons Attribution International License (CC BY). http://creativecommons.org/licenses/by/4.0/

CC) (i) Open Access

\section{Abstract}

Background: Mental health has been a largely neglected issue among Men Who Have Sex with Men (MSM) across the world. This study examines the prevalence and correlates of depression among MSM. Data and Methods: Data for this study are used from a cross-sectional Behavioral Tracking Survey-2012 conducted among 1176 MSM from Andhra Pradesh (undivided), a southern state of India. Depression of MSM was assessed using Patient Health Questionnaire-2 scale. Descriptive statistics, bivariate and multivariate logistic regression techniques were used for analysis. Results: More than one-third of MSMs (35\%) in the survey reported to have depression. The likelihood of experiencing depression was 5 times higher among MSM who were mobile for sex work outside their place of residence (55\% vs 17\%, AOR: 5.2, 95\% CI: $3.7-7.3$ ) and had experienced physical or sexual violence $(82 \%$ vs $33 \%$, AOR: $6.0,95 \%$ CI: 2.1 - 17.4) than their respective counterparts. Rates of depression were significantly higher among MSM who had experienced Sexually Transmitted Infections symptoms; knowledge of their HIV positivity; who didn't use condoms during anal sex with any clients/partners; those who consumed alcohol and were in financial debt at the time of survey than others. Those who were associated with any community groups have significantly less chances of reporting depression. Discussion: The study certainly highlighted that the HIV prevention efforts with MSM in India require an integrated approach on addressing the mental health issues. To support this, programs and research-based evidence will be highly needed to ensure that mental health issues are properly addressed among MSM and other high risk groups.

\section{Keywords}

Mental Health, Depression, PHQ-2 Scale, MSM, High Risk Population, South India

\footnotetext{
${ }^{*}$ Corresponding author.
} 


\section{Introduction}

Mental health problems are key contributors to the global burden of disease and disability, contributing to nearly $13 \%$ of the total burden of disease globally [1]. Mental health, as an integral part of overall well-being, has been a largely neglected issue among marginalized populations in the developing world. Globally, men who have sex with men (MSM), a marginalized group, face several health-related challenges, including HIV risk, stigma and discrimination, which have been empirically documented [2]. Studies worldwide reveal that MSM have higher rates of risky sexual behavior, HIV infection, depression, suicidal attempts than other populations [3]-[9]. In a mental health study conducted in the Netherlands, the 12-month and lifetime prevalence of major depression and dysthymia (i.e., less severe, chronic depression) was nearly three times higher among MSM than non-MSM [10]; national household and population-based studies in the US demonstrate similar findings [11]-[13].

Studies in Australia document that discrimination and social exclusion are key determinants of elevated risk of mental ill-health and suicidality among high-risk LGBTI (lesbian, gay, bisexual, trans-gender and intersex sexuality) population [14] [15]. In a study in Shanghai, China, lack of social support was found to be a factor influencing high rates of depression among MSM [16]. Poor mental health is shown to increase high-risk behaviors in low- and middle-income countries [17]-[20]. Research has also revealed that poor psychosocial health contributes to increased sexual risk behavior and decreased use of HIV prevention services [2] [7] [21] [22]. High-risk groups, including MSM who are mentally depressed, engage in unprotected sex, substance abuse and erratic behaviors [17] [19] [23]. Several studies demonstrate a significant association between depressive symptoms, risky sexual behavior, Sexually Transmitted Infections (STI) symptoms and HIV risk among MSM [7] [24]-[27]. A study in the US documents that MSM reporting high levels of depressive symptoms were also using substances and engaging in both unprotected receptive and insertive anal intercourse, and sex with a risky partner [28]. A systematic review study suggests that MSM who face violence are more likely to engage in substance use, suffer from depressive symptoms, be HIV positive, and engage in unprotected anal sex, and MSM who perpetrate intimate partner violence are more likely to engage in substance use [29]. Engaging in unprotected sex is related to low self-esteem due to marginalization and stigma [30].

Given the concern regarding the high rates of HIV/AIDS among MSM, most preventive interventions have focused on the risks associated with the transmission of HIV/AIDS. As a result the psychosocial and mental health needs of MSM have been largely ignored. In India, the national HIV prevention program implemented by the National AIDS Control Organization (NACO), and supported by Avahan-India AIDS Initiative in south India focuses on behavioral change communication, provision of STI services and commodities, and building a referral network for HIV testing and provision of antiretroviral (ARV) treatment and structural interventions. However, psycho-social needs, mental health problems, rehabilitation and counselling services have not integrated into the HIV prevention program. Mental health issues among MSM in India have been largely understudied although issues focusing on mental health of female sex workers were studied to a certain extent [31]. To our knowledge, only two studies have explored mental health issues among MSM in India and both these are micro-level studies, with small samples, focusing only on two cities in India [7] [27]. Our study attempts to fill this research gap by understanding the prevalence of mental depression among MSM in India, and examining the factors associated with depression among MSM. Such research is important in the Indian and global context giving the marginalization of MSM due to stigma, discrimination and HIV risk.

\section{Data and Methods}

\subsection{Data}

This study used data from the Behavioral Tracking Survey-2012 (BTS), a cross-sectional survey conducted among MSM between January and February 2012 in Andhra Pradesh (the state was divided into two separate states as Andhra Pradesh and Telengana from 2nd June, 2014), a state in southern India. The objective of the survey was to monitor the HIV prevention activities of Avahan, the India AIDS Initiative. The survey gathered information on condom use, HIV/AIDS knowledge, community mobilization, STI treatment, along with information on the mental health status of MSM using the Patient Health Questionnaire-2 (PHQ-2) depression scale.

MSM were randomly recruited for the survey from three program districts (namely, Khammam, Kurnool and Ananthapur) of Andhra Pradesh a southern state of India, from a total of 23 districts where the Avahan program 
is implementing HIV prevention interventions for high risk groups. For each district, a sample size of 400 MSM was calculated based on the prevalence of consistent condom use. The sampling frame was prepared by selecting MSM from each hot spot (place where MSM congregate to solicit clients). A rapid mapping exercise was conducted using key informant interviews with local community members, the police, and social workers, to validate the list of hot spots originally developed by the program-implementing agency. The hot spots were then grouped into two categories: 1) non-public (hotels, lodges, roadside cafes, and homes); and 2) public (streets, market areas, highways, and cinemas). A probability sampling method was used to select respondents. The conventional cluster sampling method was used for non-public hot spots and the time-location cluster (TLC) sampling method was used for public hot spots [32] [33]. The TLC method involved dividing a hot spot into several clusters based on the time slots (e.g., 5 pm - 9 pm) when MSM gathered at the hot spot, and then randomly selecting the required number of clusters. In the second stage, respondents were randomly selected within each selected hot spot. A total sample of 1176 MSM was collected.

All interviews were conducted by trained male interviewers, with verbal and written skills in Telugu, the local language of Andhra Pradesh. The survey instrument (structured questionnaire for MSM) was developed in English and translated into Telugu. The translated forms were reviewed by study investigators fluent in both languages. The interview schedule was pre-tested in communities similar to the survey sites. All the interviews were held in a private location specifically hired for the survey or in a location convenient to the study participants. Field staff checked the data immediately after the interviews to ensure accuracy and completeness of the questionnaires. A user-written computer program in CSPro (version 4.1) was used for double data entry by trained data entry officers.

The BTS design and questionnaires were approved by the institutional review boards of Family Health International and the Karnataka Health Promotion Trust. Verbal consent was obtained from all respondents prior to participation in the interview. The eligibility criteria for inclusion in the survey was 'any man or hijra (transgender), self-identified MSM, aged 18 years or above, who had sex with another male in exchange of cash/kind and who were soliciting clients at street corners, highways and pick-up points within the operational area and the information were collected accordingly in this survey. Participants were not compensated for their time in the survey but were referred to project services run by implementing agencies in the study districts.

\subsection{Measures}

The socio-demographic and behavioral variables used for the analysis were age ( $<30$ years, $\geq 30$ years); marital status (never married, currently married, and widower/divorced/separated/deserted); formal education (no, yes); usual place of practicing sex work (rural, urban/semi-urban); work other than sex work (sex work only or working somewhere else as well); Information on typology was captured by asking respondents to self-identify into subcategories of sexual identities such as (Kothi: predominantly receptive during anal sex, Panthi: predominantly insertive during anal sex, $A C / D C$ or double decker: engaged in both insertive and receptive anal sex and Hijra (transgender)); in debt at the time of survey (no, yes); mobility for sex work within and/or outside district in the past 2 years (no, yes); condom use with clients or partners during anal sex in the past 1 year (no, yes); experienced physical or sexual violence in the past 6 months (no, yes); consume alcohol in the past 30 days (no, yes); experienced discrimination at public places (e.g. health facilities, post office and banks etc.) related to being a MSM (low, high); experienced any STI symptoms in the past 6 months (no, yes); HIV status at the time of survey (self-reported) (known negative, known positive and did not want to report); and association with any community groups (e.g. self-help groups or community based organizations) (no, yes).

In this study, mental health status is the dependent variable, and was measured using the PHQ-2 depression scale. The PHQ-2 scale is used for screening mental depression based on the frequency of depressed moods and anhedonia (i.e. inability to experience pleasure from activities usually found enjoyable) [34] [35]. In this study, MSM were asked two questions (from the PHQ-2 scale) during the survey: how often have you been bothered over the past two weeks: 1) little or no interest or pleasure in doing things; 2) feeling down, depressed or hopeless. Answers were recorded in one of the following four categories, 0: not at all; 1: several days; 2: more than half the days; and 3: nearly every day. The total score ranging from 0 - 6 was calculated, and in the present study, we have recoded the scores as reporting any depressive symptoms or depression (for score 1 to $5=1$ ) and reporting no depression (for score $0=0$ ). 


\subsection{Data Analysis}

Descriptive statistics (i.e., means, standard deviations, and proportions) and bivariate analyses were used to describe the strength and association of MSM's socio-demographic/behavioral characteristics and the outcome indicator. The respective p-values for the bivariate analysis were calculated using the chi-square test. Adjusted odds ratios (AOR) and their 95\% confidence intervals (CI) were estimated through multivariate logistic regression, after adjusting for background characteristics, to assess the independent relationships of degree of mental depression with the potential economic, behavioral, STI and HIV status, and community association variables. All analyses were conducted using STATA software (version 11.2).

\section{Results}

More than three-fifths of MSM included in the study were less than 30 years of age (64\%), literate (74\%), never married (61\%) and belonged to Kothi typology (66\%). More than one-third of MSM (35\%) reported experiencing of any depression (Table 1). Among MSM with any depression, more than half were less than 30 years of age (53\%) and were practicing sex work in urban/semi-urban areas (64\%). Most of the MSM who reported depression were educated (78\%) and were working elsewhere in addition to sex work (84\%) (Table 2). More than two-fifths were either never married or currently married and predominantly belonged to Kothi typology (46\% each).

The AORs calculated here were adjusted for age, education, marital status, usual place of practicing sex work and work other than sex work (Table 3). Results show that the likelihood of experiencing depression was significantly higher among MSM belongs to Panthi typology (64\% vs 24\%, AOR: 5.0, 95\% CI: 3.0 - 8.5); who were mobile for sex work within and outside the district (55\% vs 17\%, AOR: 5.2, 95\% CI: $3.7-7.3$ ) and had experienced physical or sexual violence in the past 6 months (82\% vs 33\%, AOR: 6.0, 95\% CI: 2.1 - 17.4) than their respective counterparts. The probability of reporting depression was significantly higher among MSM who belonged to AC/DC (51\% vs 24\%, AOR: 3.2, 95\% CI: 2.1 - 4.8) and Hijra typology (58\% vs 24\%, AOR: 3.2, 95\% CI: 1.6 - 6.3); had experienced STI symptoms in the past 6 months (59\% vs 32\%, AOR: 3.1, 95\% CI: 1.9 - 5.0); were aware of their HIV-positivity status (51\% vs 30\%, AOR: 2.4, 95\% CI: 1.2 - 4.7) and who did not want to report their HIV status (51\% vs 30\%, AOR: 2.6, 95\% CI: 1.7 - 3.8) as compared to others. The odds of reporting depression was two times higher among MSM who did not use condoms during anal sex with any clients/partners in the past one year (82\% vs 33\%, AOR: 2.0, 95\% CI: 1.5 - 2.7); consumed alcohol in the past one month (50\% vs $25 \%$, AOR: 2.3 , $95 \%$ CI: $1.7-3.2)$ and were in debt at the time of survey (41\% vs $26 \%$, AOR: $2.0,95 \%$ CI: 1.4 - 2.6) than their counter parts. Those who were associated with any community group had a $50 \%$ less likelihood of reporting depression (34\% vs 38\%, AOR: 0.5, 95\% CI: $0.3-0.9$ ) than others.

Table 1. Mental health status (any depression) as reported by MSM in Andhra Pradesh, India, 2012.

\begin{tabular}{lc}
\hline \multicolumn{1}{c}{ Indicators } & Percentage \\
\hline In the past two weeks, how often have you been experiencing little or no interest or pleasure in doing things & 68.0 \\
Not at all & 27.4 \\
Several days & 4.3 \\
More than half the days & 0.3 \\
Nearly every day & 72.7 \\
In the past two weeks, how often have you been experiencing feeling down, depressed or hopeless & 24.1 \\
Not at all & 2.0 \\
Several days & 1.2 \\
More than half the days & \\
Nearly every day & 65.4 \\
Mental health status index & 34.6 \\
No depression & $\mathbf{1 0 0 . 0}$ \\
Any depression & $(\mathbf{1 1 7 6})$ \\
$\mathbf{N}$ &
\end{tabular}


Table 2. Background characteristics of MSMs who reported any depression in Andhra Pradesh, India, 2012.

\begin{tabular}{|c|c|c|c|c|}
\hline \multirow{2}{*}{ Background characteristics } & \multirow{2}{*}{ \% (n) or Mean (SD) } & \multicolumn{3}{|c|}{ Mental health status } \\
\hline & & No depression & Depression & P-value \\
\hline Age (Mean, SD) & $28.4(6.5)$ & $27.4(6.1)$ & $30.1(6.8)$ & \\
\hline Age & & & & 0.000 \\
\hline$<30$ years & $64.4(757)$ & $70.6(543)$ & $52.5(214)$ & \\
\hline$\geq 30$ years & $35.6(419)$ & $29.4(226)$ & 47.5 (193) & \\
\hline Education & & & & 0.058 \\
\hline No formal education & 25.8 (303) & 27.7 (213) & $22.3(91)$ & \\
\hline Having formal education & $74.2(873)$ & $72.3(557)$ & $77.7(316)$ & \\
\hline Marital status & & & & 0.000 \\
\hline Never married & $60.8(715)$ & 68.4 (526) & 46.2 (188) & \\
\hline Currently married & $35.1(413)$ & $29.3(225)$ & $46.2(188)$ & \\
\hline Widower/deserted/separated/divorced & $4.1(48)$ & 2.3 (18) & $7.6(31)$ & \\
\hline Typology & & & & 0.000 \\
\hline Kothi (anal receptive) & $66.1(778)$ & $77.0(592)$ & $45.7(186)$ & \\
\hline Panthi (anal penetrative) & $9.8(115)$ & $5.4(41)$ & $18.2(74)$ & \\
\hline AC/DC (receptive \& penetrative) & 19.5 (229) & $14.7(113)$ & $28.5(116)$ & \\
\hline Hijra & $4.6(54)$ & $3.0(23)$ & $7.6(31)$ & \\
\hline Usual area of practising sex work & & & & 0.000 \\
\hline Rural & 22.5 (265) & $15.2(117)$ & $36.5(148)$ & \\
\hline Urban/Semi-urban & $77.5(911)$ & $84.8(653)$ & $63.5(258)$ & \\
\hline Work other than sex work & & & & 0.114 \\
\hline Sex work only & 13.5 (159) & $12.3(95)$ & $16.0(65)$ & \\
\hline Working somewhere else also & $86.5(1017)$ & $87.7(675)$ & $84.1(342)$ & \\
\hline In debt at the time of survey & & & & 0.000 \\
\hline No & $43.4(510)$ & $49.1(378)$ & $32.5(132)$ & \\
\hline Yes & $56.6(666)$ & $50.9(391)$ & $67.5(275)$ & \\
\hline \multicolumn{2}{|c|}{ Mobility for sex work within and/or outside district in the past 2 years } & & & 0.000 \\
\hline No & $54.2(638)$ & $68.8(529)$ & 26.7 (109) & \\
\hline Yes & $45.8(538)$ & $31.2(240)$ & $73.3(298)$ & \\
\hline \multicolumn{2}{|c|}{ Condom use with clients/partners during anal sex in past one year } & & & 0.000 \\
\hline Yes & $43.2(482)$ & $62.9(460)$ & $45.4(174)$ & \\
\hline No & $56.8(634)$ & $37.1(272)$ & $54.6(210)$ & \\
\hline \multicolumn{2}{|c|}{ Experienced physical or sexual violence, past 6 months } & & & 0.000 \\
\hline No & $95.8(1127)$ & $98.9(761)$ & $90.0(366)$ & \\
\hline Yes & $4.2(49)$ & $1.2(09)$ & $10.0(41)$ & \\
\hline \multicolumn{2}{|l|}{ Consumed alcohol in past 30 days } & & & 0.000 \\
\hline No & $48.5(583)$ & $70.3(541)$ & $43.2(176)$ & \\
\hline Yes & $51.5(618)$ & 29.7 (229) & $56.8(231)$ & \\
\hline \multicolumn{2}{|l|}{ Experienced discrimination at public places } & & & 0.010 \\
\hline Low & $10.0(116)$ & $11.4(88)$ & $7.0(28)$ & \\
\hline High & $90.0(1060)$ & $88.6(682)$ & $93.0(378)$ & \\
\hline \multicolumn{2}{|c|}{ Experienced any STI symptoms, past 6 months } & & & 0.000 \\
\hline No & $89.0(1046)$ & $93.0(715)$ & $81.3(331)$ & \\
\hline Yes & $11.0(130)$ & $7.0(54)$ & $18.7(76)$ & \\
\hline \multicolumn{2}{|c|}{ HIV status at the time of survey (self-reported) } & & & 0.000 \\
\hline Known Negative & 78.9 (927) & $84.2(648)$ & $68.9(280)$ & \\
\hline Known Positive & $3.6(43)$ & $2.7(21)$ & $5.3(22)$ & \\
\hline Did not want to report & $17.5(206)$ & $13.1(101)$ & $25.8(105)$ & \\
\hline \multicolumn{2}{|l|}{ Association with community groups } & & & 0.461 \\
\hline No & $8.5(99)$ & $8.0(61)$ & 9.3 (38) & \\
\hline Yes & 91.5 (1077) & $92.0(708)$ & 90.7 (369) & \\
\hline Total & $100.0(1176)$ & $100.0(769)$ & $100.0(407)$ & \\
\hline
\end{tabular}

Note: p-value were calculated through chi-square test. 
Table 3. Association between selected socioeconomic and behavioral characteristics, and depression among MSMs in Andhra Pradesh, India, 2012.

\begin{tabular}{|c|c|c|}
\hline Background characteristics & \% Having depression (n) & AOR (95\% CI) \\
\hline \multicolumn{3}{|l|}{ Typology } \\
\hline Kothi & $24.0(186)$ & Referent \\
\hline Panthi & $64.3(74)$ & $5.0(3.0-8.5)^{* * *}$ \\
\hline $\mathrm{AC} / \mathrm{DC}$ & $50.5(116)$ & $3.2(2.1-4.8)^{* * *}$ \\
\hline Hijra & $57.6(31)$ & $3.2(1.6-6.3)^{* * *}$ \\
\hline \multicolumn{3}{|l|}{ In debt at the time of survey } \\
\hline No & $26.0(132)$ & Referent \\
\hline Yes & $41.2(275)$ & $2.0(1.4-2.6)^{* * *}$ \\
\hline \multicolumn{3}{|c|}{ Mobility for sex work within and/or outside district in the past 2 years } \\
\hline No & $17.0(109)$ & Referent \\
\hline Yes & $55.4(298)$ & $5.2(3.7-7.3)^{* * *}$ \\
\hline \multicolumn{3}{|c|}{ Use of condom during anal sex with any clients/partners in past one year } \\
\hline Yes & $27.5(174)$ & Referent \\
\hline No & $43.5(210)$ & $2.0(1.5-2.7)^{* * *}$ \\
\hline \multicolumn{3}{|l|}{ Experienced physical or sexual violence, past 6 months } \\
\hline No & $32.5(366)$ & Referent \\
\hline Yes & $82.1(41)$ & $6.0(2.1-17.4)^{* * *}$ \\
\hline \multicolumn{3}{|l|}{ Alcohol use in past 30 days } \\
\hline No & $24.5(176)$ & Referent \\
\hline Yes & $50.2(231)$ & $2.3(1.7-3.2)^{* * *}$ \\
\hline \multicolumn{3}{|l|}{ Experienced discrimination at public places } \\
\hline Low & $24.4(28)$ & Referent \\
\hline High & $35.7(378)$ & $1.5(0.9-2.7)$ \\
\hline \multicolumn{3}{|l|}{ Experience of STI symptoms, past 6 months } \\
\hline No & $31.6(331)$ & Referent \\
\hline Yes & $58.5(76)$ & $3.1(1.9-5.0)^{* * *}$ \\
\hline \multicolumn{3}{|l|}{ HIV status at the time of survey (self - reported) } \\
\hline Known negative & $30.2(280)$ & Referent \\
\hline Known positive & $50.6(22)$ & $2.4(1.2-4.7)^{* *}$ \\
\hline Did not want to report & $51.0(105)$ & $2.6(1.7-3.8)^{* * *}$ \\
\hline \multicolumn{3}{|l|}{ Association with community groups } \\
\hline No & $38.2(38)$ & \\
\hline Yes & $34.2(369)$ & $0.5(0.3-0.9)^{* *}$ \\
\hline
\end{tabular}

Note: CI: Confidence Interval; AOR: Adjusted Odds Ratio; AOR are adjusted for age, education, marital status, usual place of practicing sex work and work status other than sex work; Dependent variable is mental depression status ( $0=$ no depression and $1=$ having any level of depression). STI symptoms includes any genital sore/ulcer and genital discharge in last 6 months; Mobility for sex works includes visited different places outside district \& had sex with clients in last two years; Association with community groups includes self-help group or community based organization.

\section{Discussion}

The findings of the study reveal that depression is highly prevalent among MSM in southern India; just over one-third of MSM reported being depressed. Depression among MSMs is significantly associated with their typology, condom use in anal sex, experience of physical or sexual violence, alcohol use, experience of STI symptoms and HIV status. Most of these findings support previous research from other countries [2] [7]-[9] [16] 
[19] [20] [22]-[29]. This study adds further that MSM who are predominantly Panthi and AC/DC, are in debt, mobile for sexual work and do not want to report their HIV status are at higher risk of having depressive symptoms. It also depicts that MSM who have association with community groups are less likely to be depressed.

It is clear from the study that depression is highly prevalent among MSM those who are economically, socially, physically and psychologically deprived, and are highly mobile. The study findings show a positive but non-significant association between reporting depression and MSM discriminated at public places. However, other studies have found that discrimination leads to depression among MSM [14] [15] [30]. Andhra Pradesh State AIDS Control Society (APSACS) and Avahan prevention program for key population began addressing reduction of stigma and discrimination of sex workers and MSM at health facilities and clinics, agencies of law enforcement and justice through sensitization and advocacy with the health care providers, police and judiciary since 2007. These initiatives may have impacted on the role of external stigma and discrimination on mental health among MSM in Andhra Pradesh. Worldwide studies demonstrate a strong association between MSM's depressive symptoms and involvement in unprotected receptive and insertive anal intercourse, HIV risk, substance abuse and other erratic behaviours [17]-[20] [23] [29]. This study shows a significant association between depression and risky sexual behavior, alcohol use and experience of violence among MSM. This study also explains that MSM who are in debt and mobile for sex work have a higher likelihood of reporting mental depression than others. It can be interpreted that MSM who are in debt and mobile are highly vulnerable to experiencing violence and depression. This study shows that MSM who have association with community groups are at lower risk of reporting depression than others, possibly because being a member of a self-help group or community-based organization or having community assistance provides MSM some amount of emotional and financial support. As a result, they feel more confident in taking their decisions, seeking services from health facilities, and speaking about their rights in public. Further, their chances of engaging in risky sexual behavior and reporting depression decrease. Similar findings are reported in Australia and China, where studies have shown that enriched social support has a negative association with depression among MSM [14]-[16]. Recognizing the role of community groups and community based organizations play in HIV prevention, "Pehchan" program is a rare example of a community systems strengthening program funded by Global Fund working at a national scale from 2010 in India. It provides organizational development, technical and capacity building support to new and existing community based organizations working with MSM-Transgender-Hijra (MTH) communities. The program leverages and complements the government's HIV prevention strategy for MTH by providing community identified and friendly services: mental health and family health counselling which are beyond basic HIV prevention program [36]. As reported, MSM are a marginalized high risk group, and social stigma and discrimination are major barriers to disclosure of MSM status and access to health care [7] [22] [30]. An integrated "cocktail" intervention has been suggested to address the sexual health, mental health and overall well-being of MSM, where both the psychological and behavioural issues can be targeted [37]. The recent Global Fund Round-9 HIV prevention program for MSM in India has developed a specialized package of basic and advanced counselling sessions to address psycho-social, mental and family issues in 19 states including Andhra Pradesh. While there are signs of success in building capacities of communities in addressing mental health issues, increasing the awareness of mental health services at government health facility and community based organizations, still continuous access to these services are a real challenge for dispersed rural MSM population. It is reported that fewer than $20 \%$ of people who need mental health care have access to treatment because of lack of services in India [38]. The study findings should be interpreted cautiously in light of certain study limitations. First, the inclusion of the PHQ-9 depression scale method in the study would have provided more information on mental health and severity of depression among MSM. Secondly, the inclusion of other variables, such as psychological violence and the availability of mental health services at government health clinics etc., would have provided better insights on the mental health situation of MSM.

\section{Conclusion}

The findings of our study underscore the need to strengthen HIV prevention programs by incorporating strategies to address mental health issues among MSM. The study indicates that there is an urgent need to integrate mental health care within the behavioral change communication component of HIV prevention and other health programs. So far the National AIDS Control Program (NACP) guidelines, the national AIDS policy and the Avahan program have largely ignored mental health problems of MSM in India. There is an urgent necessity to 
identify the mental health problems, as well as design and implement strategies for accessible and efficient mental health services at government health facilities, STD clinics and voluntary counselling and testing centres for MSM in India. Better mental health is crucial to achieve the overall health status of any population. Although, India's National Mental Health Program was introduced in 1982, it has not yet been fully operationalized. More importantly, government and policymakers need to acknowledge that mental health is an important issue among marginalized population groups, like MSM. This study strongly recommends further research and advocacy based on evidence to ensure that mental health issues are properly addressed.

\section{Acknowledgements}

This paper was written as part of the Knowledge Network Project (KNP) of the Population Council, which is a grantee of the Bill \& Melinda Gates Foundation through Avahan-India AIDS Initiative. The views expressed herein are those of the authors and do not necessarily reflect the official policy or position of the Bill \& Melinda Gates Foundation and Avahan. We would like to thank Ms. Deepika Ganju for her editorial support and inputs on an earlier version of the paper.

\section{Declaration of Interest}

There is no conflict of interest in the present study for any of the authors.

\section{References}

[1] WHO (2011) Mental Health Atlas, 2011. World Health Organization, Geneva.

[2] UN (2007) Men Who have Sex with Men: The Missing Piece in National Responses to AIDS in Asia and the Pacific. United Nations, Geneva.

[3] Herek, G.M. and Garnets, L.D. (2007) Sexual Orientation and Mental Health. Annual Review of Clinical Psychology, 3, 353-375. http://dx.doi.org/10.1146/annurev.clinpsy.3.022806.091510

[4] CDC (2008) HIV Survelliance Report 2008. Centre for Disease Control, Atlanta.

[5] Corboz, J., et al. (2008) Feeling Queer and Blue: A Review of the Literature on Depression and Related Issues among Gay, Lesbian, Bisexual and Other Homosexually Active People. LaTrobe University, Melbourne.

[6] SPA (2009) Position Statement Suicide and Self-Harm among Gay, Lesbian, Bisexual and Transgender Communities. Suicide Prevention Australia, Sydney.

[7] Safren, S.A., Thomas, B.E., Mimiaga, M.J., Chandrasekaran, V., Menon, S., Swaminathan, S. and Mayer, K.H. (2009) Depressive Symptoms and Human Immunodeficiency Virus Risk Behavior among Men Who Have Sex with Men in Chennai, India. Psychology, Health \& Medicine, 14, 705-715. http://dx.doi.org/10.1080/13548500903334754

[8] Alvy, L.M., McKirnan, D.J., Mansergh, G., Koblin, B., Colfax, G.N., Flores, S.A. and Hudson, S. (2011) Depression Is Associated with Sexual Risk among Men Who Have Sex with Men, But Is Mediated by Cognitive Escape and SelfEfficacy. AIDS and Behavior, 15, 1171-1179. http://dx.doi.org/10.1007/s10461-010-9678-z

[9] Leonard, W., et al. (2012) Private Lives 2: The Second National Survey of the Health and Wellbeing of Gay, Lesbian, Bisexual and Transgender (GLBT) Australians. Australian Research Centre in Sex, Health and Society, LaTrobe University, Melbourne.

[10] Sandfort, T.G., de Graaf, R., Bijl, R.V. and Schnabel, P. (2001) Same-Sex Sexual Behavior and Psychiatric Disorders: Findings from the Netherlands Mental Health Survey and Incidence Study (NEMESIS). Archives of General Psychiatry, 58, 85-91. http://dx.doi.org/10.1001/archpsyc.58.1.85

[11] Cochran, S.D. and Mays, V.M. (2000) Lifetime Prevalence of Suicide Symptoms and Affective Disorders among Men Reporting Same-Sex Sexual Partners: Results from NHANES III. American Journal of Public Health, 90, 573-578. http://dx.doi.org/10.2105/AJPH.90.4.573

[12] Cochran, S.D., Mays, V.M. and Sullivan, J.G. (2003) Prevalence of Mental Disorders, Psychological Distress, and Mental Health Services Use among Lesbian, Gay, and Bisexual Adults in the United States. Journal of Consulting and Clinical Psychology, 71, 53-61. http://dx.doi.org/10.1037/0022-006X.71.1.53

[13] Mills, T.C., Paul, J., Stall, R., Pollack, L., Canchola, J., Chang, Y.J., Moskowitz, J.T. and Catania, J.A. (2004) Distress and Depression in Men Who Have Sex with Men: The Urban Men’s Health Study. American Journal of Psychiatry, 161, 278-285. http://dx.doi.org/10.1176/appi.ajp.161.2.278

[14] Wilkinson, R. and Marmot, M. (2003) Social Determinants of Health-The Solid Facts. World Health Organization, Geneva. 
[15] Rosenstreich, G. (2011) Discrimination, LGBTI Mental Health and Suicide. Australian Journal on Psychosocial Rehabilitation Spring, 2011, 16-19.

[16] Yan, H., Wong, F.Y., Zheng, T., Ning, Z., Ding, Y., Nehl, E.J., Lin, L. and He, N. (2014) Social Support and Depressive Symptoms among "Money” Boys and General Men Who Have Sex with Men in Shanghai, China. Sex Health, 11, 285-287. http://dx.doi.org/10.1071/SH14017

[17] Savin-Williams, R. (1994) Verbal and Physical Abuse as Stressors in the Lives of Lesbian, Gay Male, and Bisexual Youths: Running away, Substance Abuse, Prostitution, and Suicide. Journal of Counseling and Clinical Psychology, 62, 261-269. http://dx.doi.org/10.1037/0022-006X.62.2.261

[18] Patel, V. (2007) Mental Health in Low- and Middle-Income Countries. British Medical Bulletin, 81-82, 81-96. http://dx.doi.org/10.1093/bmb/ldm010

[19] Collins, P.Y., Holman, A.R., Freeman, M.C. and Patel, V. (2006) What Is the Relevance of Mental Health to HIV/ AIDS Care and Treatment Programs in Developing Countries? A Systematic Review. AIDS, 20, 1571-1582. http://dx.doi.org/10.1097/01.aids.0000238402.70379.d4

[20] Freeman, M., Patel, V., Collins, P.Y. and Bertolote, J. (2005) Integrating Mental Health in Global Initiatives for HIV/ AIDS. British Journal of Psychiatry, 187, 1-3. http://dx.doi.org/10.1192/bjp.187.1.1

[21] Diaz, R.M., Ayala, G. and Bein, E. (2004) Sexual Risk as an Outcome of Social Oppression: Data from a Probability Sample of Latino Gay Men in Three U.S. Cities. Cultural Diversity \& Ethnic Minority Psychology, 10, 255-267. http://dx.doi.org/10.1037/1099-9809.10.3.255

[22] Deuba, K., Ekstrom, A.M., Shrestha, R., Ionita, G., Bhatta, L. and Karki, D.K. (2013) Psychosocial Health Problems Associated with Increased HIV Risk Behavior among Men Who Have Sex with Men in Nepal: A Cross-Sectional Survey. PLoS ONE, 8, e58099. http://dx.doi.org/10.1371/journal.pone.0058099

[23] Hutton, H.E., Lyketsos, C.G., Zenilman, J.M., Thompson, R.E. and Erbelding, E.J. (2004) Depression and HIV Risk Behaviors among Patients in a Sexually Transmitted Disease Clinic. American Journal of Psychiatry, 161, 912-914. http://dx.doi.org/10.1176/appi.ajp.161.5.912

[24] Klein, H. (2014) Depression and HIV Risk Taking among Men Who Have Sex with Other Men and Who Use the Internet to Find Partners for Unprotected Sex. Journal of Gay \& Lesbian Mental Health, 18, 164-189. http://dx.doi.org/10.1080/19359705.2013.834858

[25] Trevor, A., Brian, M., Daniel, T., Pamina, M., Ron, D., Pamela, J. and Michael, P. (2014) Depression and Sexual Dysfunction among HIV-Positive and HIV-Negative Men Who Have Sex with Men: Mediation by Use of Antidepressants and Recreational Stimulants. Archives of Sexual Behavior, 44, 399-409. http://dx.doi.org/10.1007/s10508-014-0279-1

[26] Houston, E., Sandfort, T., Dolezal, C. and Carballo-Dieguez, A. (2012) Depressive Symptoms among MSM Who Engage in Bareback Sex: Does Mood Matter? AIDS and Behavior, 16, 2209-2215. http://dx.doi.org/10.1007/s10461-012-0156-7

[27] Prajapati, A.C., Parikh, S. and Bala, D.V. (2014) A Study of Mental Health Status of Men Who Have Sex with Men in Ahmedabad City. Indian Journal of Psychiatry, 56, 161-164. http://dx.doi.org/10.4103/0019-5545.130498

[28] Fendrich, M., Avci, O., Johnson, T.P. and Mackesy-Amiti, M.E. (2013) Depression, Substance Use and HIV Risk in a Probability Sample of Men Who Have Sex with Men. Addictive Behaviors, 38, 1715-1718. http://dx.doi.org/10.1016/j.addbeh.2012.09.005

[29] Buller, A.M., Devries, K.M., Howard, L.M. and Bacchus, L.J. (2014) Associations between Intimate Partner Violence and Health among Men Who Have Sex with Men: A Systematic Review and Meta-Analysis. PLoS Medicine, 11, e1001609. http://dx.doi.org/10.1371/journal.pmed.1001609

[30] Thomas, B., Mimiaga, M.J., Kumar, S., Swaminathan, S., Safren, S.A. and Mayer, K.H. (2011) HIV in Indian MSM: Reasons for a Concentrated Epidemic \& Strategies for Prevention. Indian Council of Medical Research, 134, 920-929. http://dx.doi.org/10.4103/0971-5916.92637

[31] Patel, S.K., Saggurti, N., Pachauri, S. and Prabhakar, P. (2015) Correlates of Mental Depression among Female Sex Workers in Southern India. Asia-Pacific Journal of Public Health, Online First. http://dx.doi.org/10.1177/1010539515601480

[32] Magnani, R., Sabin, K., Saidel, T. and Heckathorn, D. (2005) Review of Sampling Hard-to-Reach and Hidden Populations for HIV Surveillance. AIDS, 19, S67-S72. http://dx.doi.org/10.1097/01.aids.0000172879.20628.e1

[33] Saidel, T., Adhikary, R., Mainkar, M., Dale, J., Loo, V., Rahman, M., Ramesh, B.M. and Paranjape, R.S. (2008) Baseline Integrated Behavioural and Biological Assessment among Most At-Risk Populations in Six High-Prevalence States of India: Design and Implementation Challenges. AIDS, 22, S17-S34. http://dx.doi.org/10.1097/01.aids.0000343761.77702.04

[34] Kroenke, K. and Spitzer, R. (2002) The PHQ-9: A New Depression Diagnostic and Severity. Psychiatric Annals, 32, 17. 
[35] Kroenke, K., Spitzer, R.L. and Williams, J.B. (2003) The Patient Health Questionnaire-2: Validity of a Two-Item Depression Screener. Medical Care, 41, 1284-1292. http://dx.doi.org/10.1097/01.MLR.0000093487.78664.3C

[36] Alliance (2014) Strengthening Capacity in MSM, Transgender and Hijra Communities to Improve HIV Prevention Impact. India HIV/AIDS Alliance.

[37] Safren, S.A., Reisner, S.L., Herrick, A., Mimiaga, M.J. and Stall, R.D. (2010) Mental Health and HIV Risk in Men Who Have Sex with Men. Journal of Acquired Immune Deficiency Syndromes, 55, S74-S77. http://dx.doi.org/10.1097/QAI.0b013e3181fbc939

[38] The Lancet (2015) Don’t Forget Health When You Talk about Human Rights. The Lancet, 385, 481. 